\title{
Inhibition of platelet-tumour cell interaction with ibrutinib reduces proliferation, migration and invasion of lung cancer cells
}

\author{
Zhiqiang Fu', Haifeng Wang ${ }^{2}$, Yi Zhou', Qi Zhou ${ }^{1 *}$ \\ ${ }^{1}$ Department of Thoracic Surgery, Shanghai Shidong Hospital, Shanghai, 200438, ${ }^{2}$ Department of Thoracic Surgery, Shanghai \\ Pulmonary Hospital, Shangai 200433, China \\ *For correspondence: Email: Zhouqicsh@163.com
}

Sent for review: 5 January 2018

Revised accepted: 27 March 2018

\begin{abstract}
Purpose: To investigate the pharmacological role of the Bruton tyrosine kinase (BTK) inhibitor, ibrutinib, in tumour cell-platelet crosstalk in lung cancer.

Methods: Human lung cancer cells A549 were treated with ibrutinib or DMSO. mRNA expression was assessed using reverse transcription-quantitative polymerase chain reaction (RT-PCR), and while western blotting was used to determine protein expression levels. Small interfering RNA (siRNA) transfection was performed to suppress the expression of galectin-3. Colony formation and Transwell $\Theta$ assays were used to determine cell viability, cell invasiveness and migratory ability.

Results: Co-culture of A549 cells and platelets induced activation of BTK/PLCY2 signalling and subsequent release of PDGF, VEGF and TGF $\beta 1$ from de-granulated platelets. However, knocking down of galectin-3 inhibited A549-induced platelet activation. Conversely, platelet activation upregulated the expression of galectin-3 via the release of PDGF. Moreover, ibrutinib significantly $(p<0.05)$ inhibited cell viability, migration, and invasion.

Conclusion: These results suggest that ibrutinib may be a novel therapeutic treatment for lung cancer.
\end{abstract}

Keywords: Bruton tyrosine kinase, Ibrutinib, Lung cancer, Platelet

\begin{abstract}
This is an Open Access article that uses a funding model which does not charge readers or their institutions for access and distributed under the terms of the Creative Commons Attribution License (http://creativecommons.org/licenses/by/4.0) and the Budapest Open Access Initiative (http://www.budapestopenaccessinitiative.org/read), which permit unrestricted use, distribution, and reproduction in any medium, provided the original work is properly credited.
\end{abstract}

Tropical Journal of Pharmaceutical Research is indexed by Science Citation Index (SciSearch), Scopus, International Pharmaceutical Abstract, Chemical Abstracts, Embase, Index Copernicus, EBSCO, African Index Medicus, JournalSeek, Journal Citation Reports/Science Edition, Directory of Open Access Journals (DOAJ), African Journal Online, Bioline International, Open-J-Gate and Pharmacy Abstracts

\section{INTRODUCTION}

Lung cancer is one of the most serious malignancies with fast-growing morbidity and mortality. Despite significant treatment advances in the past decades, the prognoses for patients with lung cancer remain very poor [1]. Limitations including drug resistance, adverse side effects, and low response have presented problems when using traditional treatments [2]. Therefore it is urgent to characterize the molecular pathogenesis of lung cancer.

Tumour cells interact and communicate with various components of the circulating system, including platelets. Platelets arising from the cytoplasm of megakaryocytes are the smallest circulating haematopoietic cells [3]. The crosstalk between platelets and tumour cells has been extensively studied for more than 100 years [4]. The contribution of circulating platelets to cancer 
progression has been suggested to be an organized process [5]. Moreover, tumours have the ability to induce activation and aggregation of platelets [6]. More effective treatments for lung cancer may be developed based on the interaction between platelets and tumour cells

Bruton tyrosine kinase (Btk) belongs to the Tec family of cytoplasmic tyrosine kinases. It is expressed in all cell lineages of the haematopoietic system, except for T-cells [7]. Given Btk is a critical molecular factor in B-cell receptor signalling, it has become an important target for the treatment of B-cell malignancies. lbrutinib is a first in class Btk inhibitor with high potency and good oral bioavailability. Ibrutinib has high clinical activity and favourable safety profile, so it has been approved for treating several B-cell lymphomas including mantle-cell lymphoma, Waldenström's macro-globulinaemia and chronic lymphocytic leukaemia [8]. In addition to its essential regulatory role downstream of BCR, Btk can also interact with, and be activated by other cell type specific receptors [9]. Furthermore, Btk is involved in important signalling pathways in platelets through the collagen receptor glycoprotein VI (GPVI). Emerging evidence has shown that Btk is involved in not only B-cell malignancies, but also in solid tumours [10]. However, the precise mechanism underlying the anti-tumour effects of Btk has not been fully elucidated.

In the present study, we investigated the role of Btk in tumour-platelet interaction in lung cancer and explored the possible molecular mechanism of this interaction.

\section{EXPERIMENTAL}

\section{Cell culture}

Human lung cancer cell lines including $\mathrm{NCl}$ H358, A549, and Calu-6 were purchased from the American Type Culture Collection (Manassas, VA, USA). The cells were cultured in Dulbecco's modified Eagle's medium (DMEM; GIBCO-BRL; Invitrogen, Carlsbad, CA, USA) containing streptomycin $(100 \mu \mathrm{g} / \mathrm{mL})$, penicillin (100 U/mL) and 10\% fetal bovine serum (FBS) and maintained in a $5 \% \mathrm{CO}_{2}$ incubator at $37^{\circ} \mathrm{C}$.

\section{Platelet preparation and cell culture}

Human platelets were freshly isolated from healthy volunteers as previously described [11]. Venous blood was collected from volunteers into $15 \%(\mathrm{v} / \mathrm{v})$ acid-citrate-dextrose and centrifuged at $180 \times \mathrm{g}$ for 10 minutes at room temperature. Platelet rich plasma (PRP) was separated and further pelleted by centrifugation at $750 \times \mathrm{g}$ for $10 \mathrm{~min}$. The platelet pellet was re-suspended in Tyrode's albumin buffer. The platelet suspension $(100 \mu \mathrm{L})$ containing $1 \times 10^{8}$ cells was added to lung cancer cells $\left(3 \times 10^{5}\right)$ and incubated for different times. For control groups, platelets were incubated with Tyrode's albumin buffer.

\section{Transfection of small interfering RNA}

The cells in logarithmic growth phase were seeded in 6-well plates at a density of $2 \times 10^{5}$ cells/well. After $24 \mathrm{~h}$ culture, the cells were transfected with negative control siRNA and small interfering RNA (siRNA; Ribo-Bio, Guangzhou, China) against galectin-3 using Lipofectamine $200{ }^{\circledR}$ (Invitrogen, Carlsbad, CA, USA) and Opti-MEM I (Gibco, Gaithersburg, MD, USA). Total RNA and protein were isolated $48 \mathrm{~h}$ post transfection. The galectin siRNA sequence was:

GGGAAUGAUGUUGCCUUCCACUUUA-3'.

\section{Reverse transcription-quantitative polymerase chain reaction (RT-qPCR)}

Total RNA was extracted from normal/tumour paired tissues and colorectal cancer (CRC) cell lines with TRIzol $^{\circledR}$ reagent (Invitrogen). The cDNA synthesis was generated with ProtoScript® first strand cDNA kit (Thermo Fisher, Waltham, MA, USA). The SYBR Green PCR kit (Thermo Fisher) was utilized for the PCR amplification. The specific primers used for the PCR were: $\beta$-actin, 5'-AAGGCCAACCGCGAGA AGAT-3' (forward) and 5'-TGATGACCTGGCC GTCAGG-3' (reverse). The sequences of galectin-3 primers were: 5'-GGCCACTGATTGT GCCTTAT-3' (forward) and 5'-TGCAACCTTG AAGTGGTCAG-3' (reverse). The $2^{-\Delta \Delta \mathrm{Ct}}$ method was used to calculate differences in mRNA expression.

\section{Colony formation assay}

The cells were seeded in 6-well culture plate at 1,000 cells/well for $24 \mathrm{hr}$, after which the medium was replaced with fresh medium. After 10 days of culture to form colonies, the cells were stained with Crystal Violet and the number of colonies was counted using a light microscope.

\section{Protein isolation and western blotting}

Total protein was extracted with RIPA buffer from Cell Signaling Technology (Danvers, MA, USA). Total proteins were then separated by SDSPAGE, transferred onto polyvinylidene difluoride (PVDF) membranes and incubated with the primary antibodies against gal-3 (1:1,000 dilution, 
\#87985), BTK (1:1,000 dilution, \#8547), p-BTK (1:1,000 dilution, \#87141), PLCY2 (1:1,000 dilution, \#3872) and p-PLCY2 (1:1,000 dilution, \#3871). The detection was performed with RapidStep $^{\text {TM }}$ ECL Reagent from EMD Millipore.

\section{Enzyme linked immunosorbent (ELISA)}

The detestation of protein levels of PDGF, VEGF and TGF $\beta 1$ were performed with ELISA assay. A549 cancer cells were co-cultured with platelets for $72 \mathrm{~h}$. The conditioned medium was collected and measured for PDGF (ab184860), VEGF (ab100663), and TGFß1 (ab100647) concentrations using ELISA kits purchased from Abcam (Cambridge, MA, USA).

\section{Cell invasion and migration assays}

The invasion and migration activities of A549 cells were determined with a standard Boyden chamber protocol. In brief, $1 \times 10^{4}$ cells were added to the upper chamber and DMEM medium containing $10 \%$ FBS were added into the lower chamber. The chambers were washed and stained with Crystal Violet after $12 \mathrm{~h}$ incubation. The cells that migrated or invaded through the membrane were counted using a light microscope (Olympus, Tokyo, Japan).

\section{Statistical analysis}

All data are expressed as mean \pm standard deviation $(S D, n=3)$. Statistical analysis was performed using SPSS statistical software for Windows, version 13.0 (SPSS, Chicago, IL, USA). Differences between groups were analysed using Student's $t$-test or one-way analysis of variance (ANOVA). A value of $p<$ 0.05 was considered statistically significant.

\section{RESULTS}

\section{Co-cultures of platelets and A549 lung cancer cells activated Btk signaling pathway}

Co-cultures of A549 cells with platelets significantly induced the upregulation of Btk tyrosine phosphorylation. However, there was no obvious change in Btk phosphorylation in $\mathrm{NCl}$ H358-platelet and calu-6-platelet co-cultures (Figure $1 \mathrm{~A}$ ). The activation status of PLCY2, the downstream effector of BTK, after the addition of platelets to A549 cells were further examined. The results showed that tyrosine phosphorylation of PLCY2 was significantly increased in platelets incubated with A549 cells (Figure 1 B). The activated platelets release the contents of granules containing serotonin, EGF, VEGF, PDGF, and TGF $\beta$, so several released factors were further measured. Consistently, the secretion of PDGF, TGF $\beta 1$, VEGF, and EGF were induced in the A549-platelet co-culture system (Figure $1 \mathrm{C}$ ). These results show that the interaction of platelets with A549 cells activated the Btk signalling pathway and induced platelet activation.

Galectin-3 mediated the activation of BTK signalling in platelets.

To verify whether galectin-3 in A549 cells mediated the activation of Btk in platelets, the expression levels of galectin-3 were measured in different cells. Figure 2 A shows that galectin-3 was highly expressed in A549 cells, whereas this expression was not detected in $\mathrm{NCl}-\mathrm{H} 358$ and Calu- 6 cells. $\beta$-lactose, the inhibitor of galectin- 3 , caused a reduction of phosphorylation of Btk and PLCY2 in a dose-dependent manner (Figure 2 B). To exclude off-target effects of lactose, galectin-3 was silenced in A549 cells with siRNA, which inhibited the induction of Btk phosphorylation by A549-platelet co-cultures (Figure $2 \mathrm{C}$ ). Taken together, these results suggest the involvement of galectin-3 in the activation of Btk during the incubation of platelets with A549 cells.

\section{Btk signalling upregulated galectin-3 expression in a positive feedback manner}

Treatment with ibrutinib, an inhibitor of Btk, significantly decreased the transcriptional levels as well as protein levels of galectin- 3 in a dosedependent manner in A549 cells (Figure $3 \mathrm{~A}$ and B). The transcriptional expression of galectin-3 can be regulated by various stimuli, including PDGF, VEGF, EGF, and TGF- $\beta$. To further identify which factor(s) were involved in the regulation of galectin-3, the A549 co-culture system was treated with different neutralizing antibodies. The data show that anti-PDGF neutralizing antibody significantly decreased the protein levels of galectin-3 (Figure $3 \mathrm{C}$ ). Together, these results indicate that BTK/PDGF activated galectin-3 in a positive dose-dependent manner.

The effect of BTK on the proliferation of A549 cells was further examined. The results show that co-cultures of A549 and platelets enhanced the proliferation of A549 cells. Ibrutinib abolished the increased proliferation of A549 cells after 48 or $72 \mathrm{~h}$ of treatment (Figure $4 \mathrm{~A}$ ). Moreover, the effects of ibrutinib on the invasion and migration capabilities of A549 cells were also investigated. A549 cells showed increased invasion and migration capabilities after treatment with platelets, whereas blockage of Btk activation with 

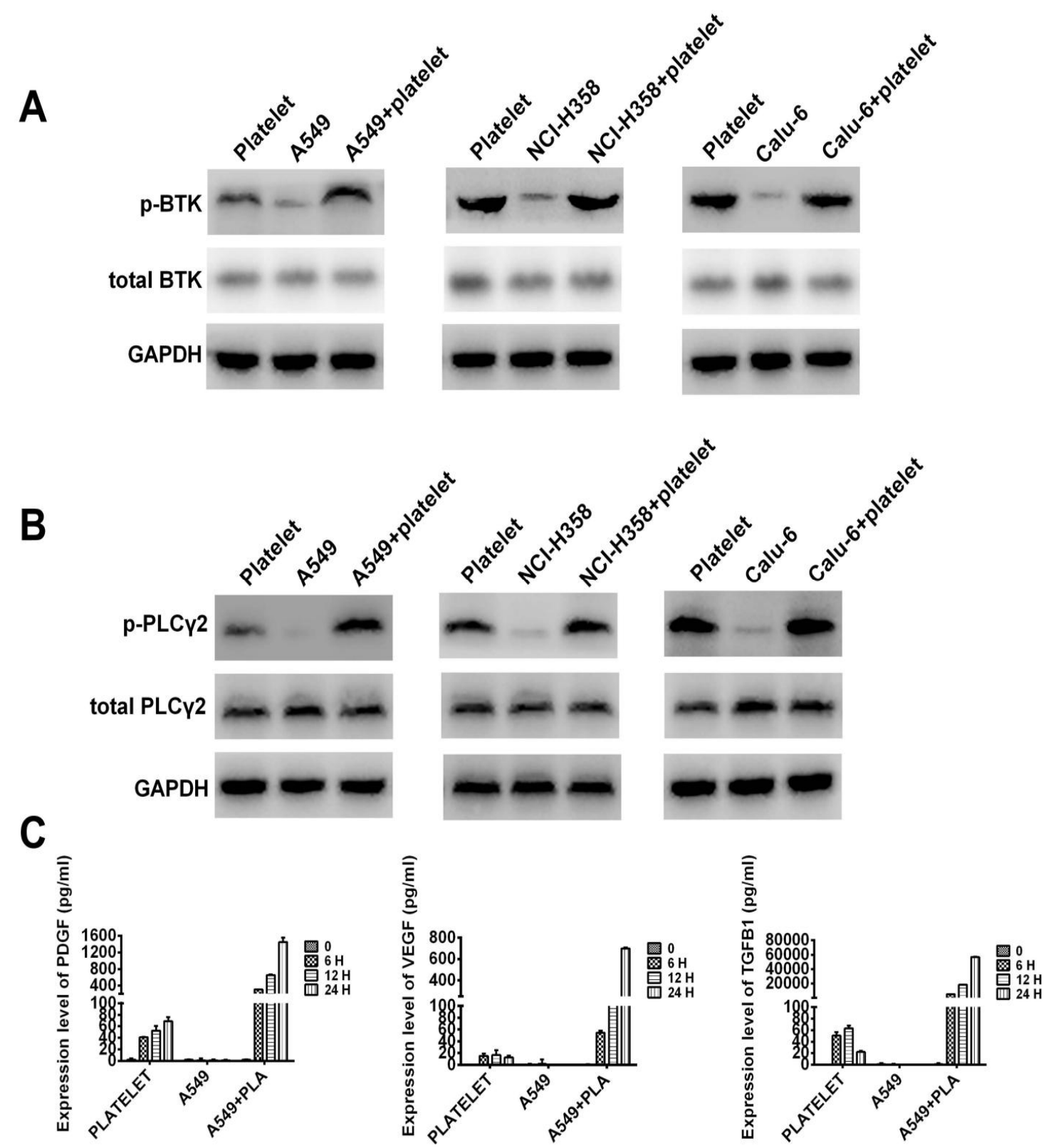

Figure 1: Co-cultures of platelets and A549 lung cancer cells activated the Btk signalling pathway. (A) Phosphorylation of Btk and total Btk levels were evaluated using western blotting. (B) The phosphorylation of PLCY2 and total PLCY2 levels were evaluated using western blotting. (C) The release of PDGF, VEGF, and TGFB1 was evaluated using an ELISA assay

ibrutinib treatment abolished the induced migration and invasion capability of A549 cells (Figure $4 \mathrm{~B}$ and $\mathrm{C}$ ). These findings suggest that a positive feedback loop was responsible for promoting the proliferation, invasion and migration capabilities of A549 cancer cells.

Pharmacological blockade of BTK activation inhibited co-culture-induced proliferation, invasion and migration capabilities of A549 tumour cells

The inhibition of co-culture-induced proliferation, invasion and migration capabilities of A549 tumour cells by lbrutinib is shown in Table 4 .

\section{DISCUSSION}

Numerous studies report the important role of interactions between circulating platelets and tumour cells during cancer progression [12]. However, the functional role of platelet-tumour crosstalk in lung cancer has not been definitively investigated. In the present study, the effect of blocking platelet-tumour cell interactions with ibrutinib on cell viability, migration, and invasion in lung cancer cells were investigated. 

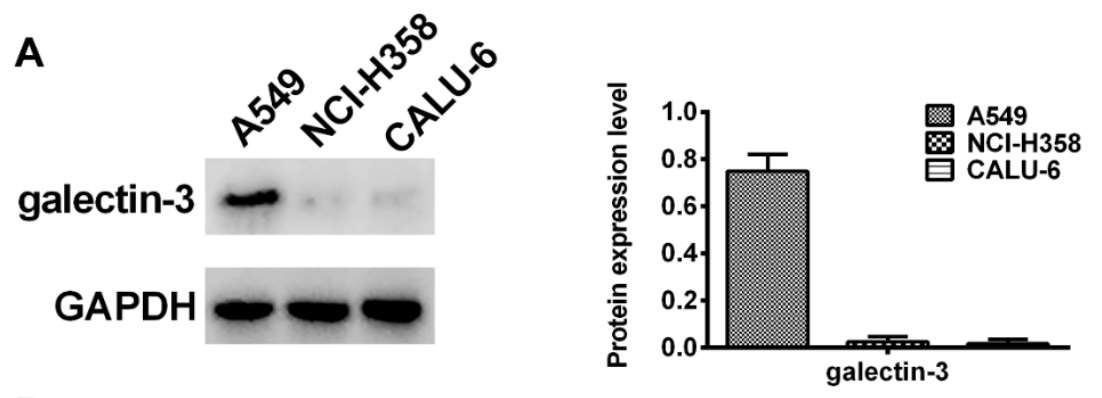

B
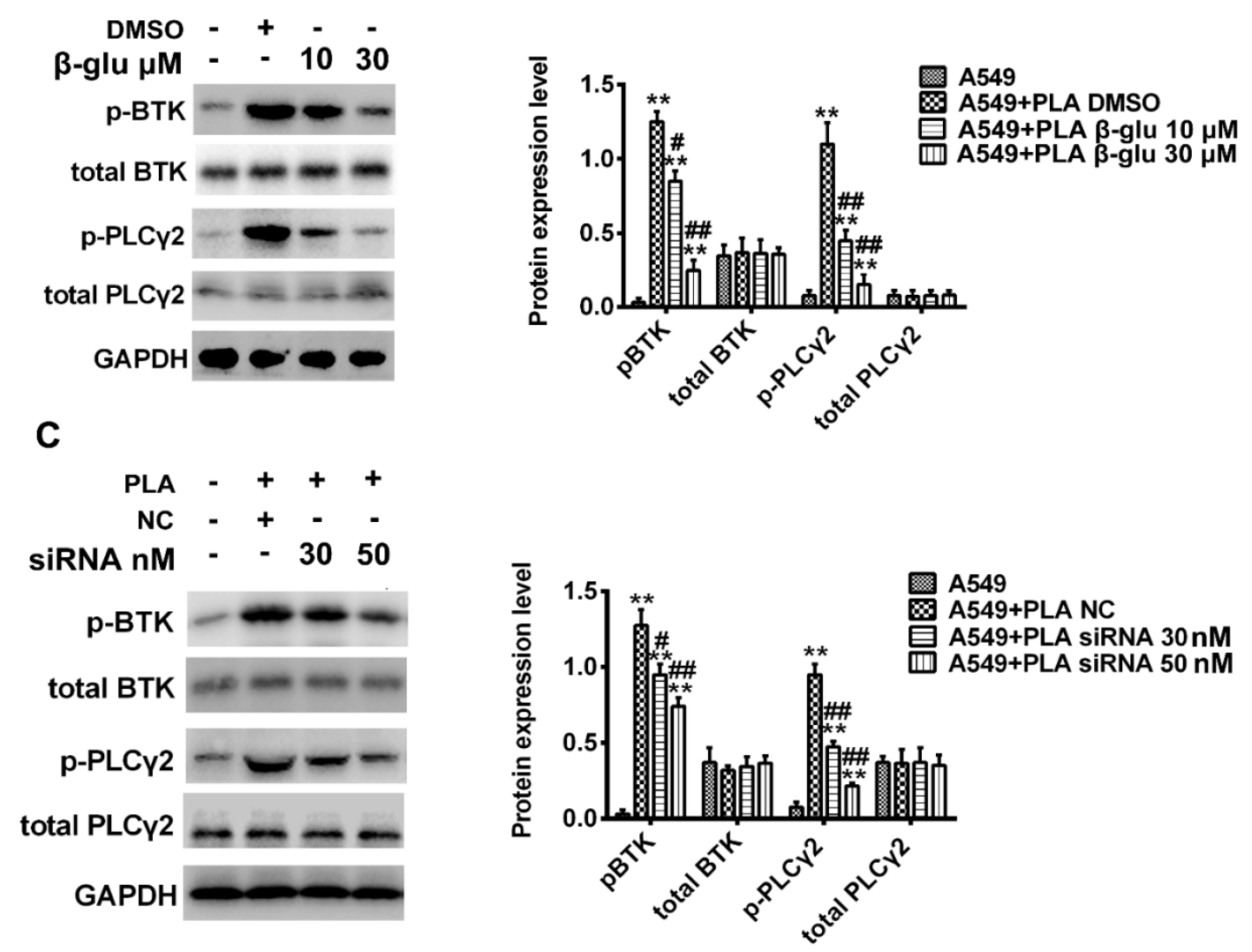

Figure 2: Galectin-3 mediated activation of BTK signalling in platelets. (A) The galectin-3 level in lung cell lines was evaluated using western blotting. (B) Co-cultures of A549 cells and platelets were treated with beta-glucose $(10$ and $30 \mu \mathrm{M})$ for $24 \mathrm{~h}$. Phosphorylation of Btk, total Btk levels, phosphorylation of PLCY2, and total PLCY2 levels were assessed using western blotting. (C) A549 cells transfected with siRNA (30 nM and $50 \mathrm{nM}$ ) specific for galectin-3 were co-cultured with platelets. Phosphorylation of Btk, total Btk levels, phosphorylation of PLCy2, and total PLCY2 levels were assessed using western blotting; ${ }^{\star *} p<0.01$ vs mock group and ${ }^{\# \#} p<0.01$ vs DMSO control. DMSO = dimethyl sulfoxide (control buffer)

The activation of platelets has been reported in various tumour subtypes. Gong et al reported much higher platelet activation levels in the circulating system of lung cancer patients relative to that of control subjects [12]. In addition, the interplay between platelet and HT29 cells coculture induced COX-2 upregulation [13]. Btk plays essential role in the modulation of platelet activation and aggregation downstream of GPVI in human platelets [14]. In the current study, the findings showed that A549 cells activated BTK/PLCy2 signalling, which led to platelet activation and degranulation.
Galectin-3 is a member of carbohydrate-binding proteins family with a high affinity for betagalactoside-containing carbohydrates [15]. It is overexpressed in various types of tumours and is involved in cancer progression and metastasis [16]. Its ectopic expression enhanced the in vitro cell motility and invasiveness of lung cancer cells [17]. Galectin-3 is also considered a possible target for KRAS-addicted lung cancer [18]. Galectin-3 contains a collagen domain and is expressed on the cell surfaces and is thought to mediate the platelet-cancer cell interplay via 
A

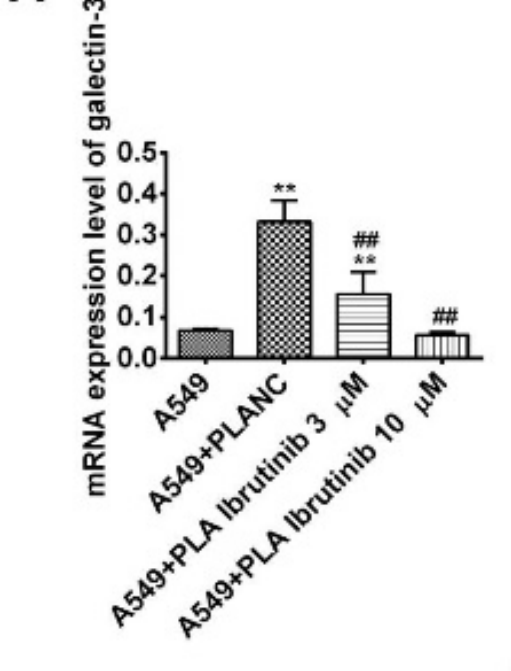

B

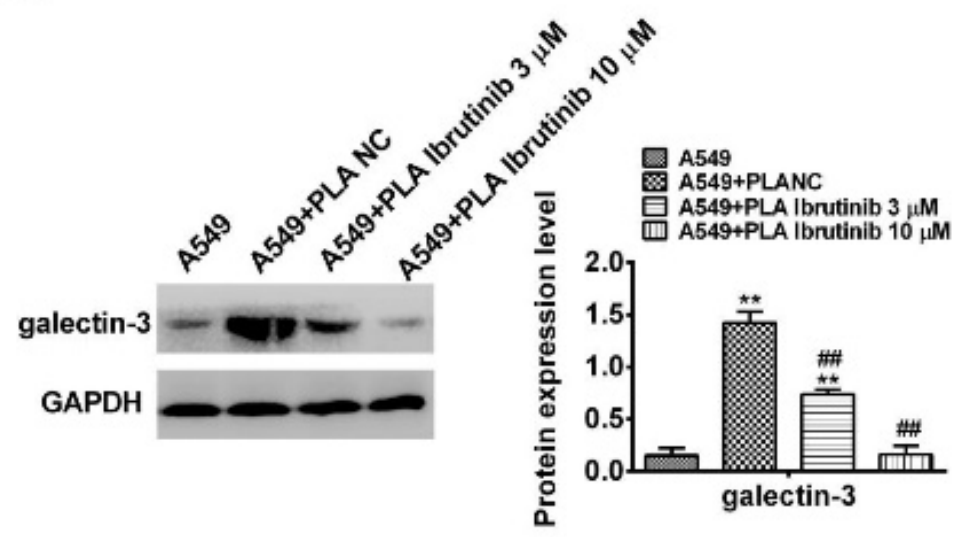

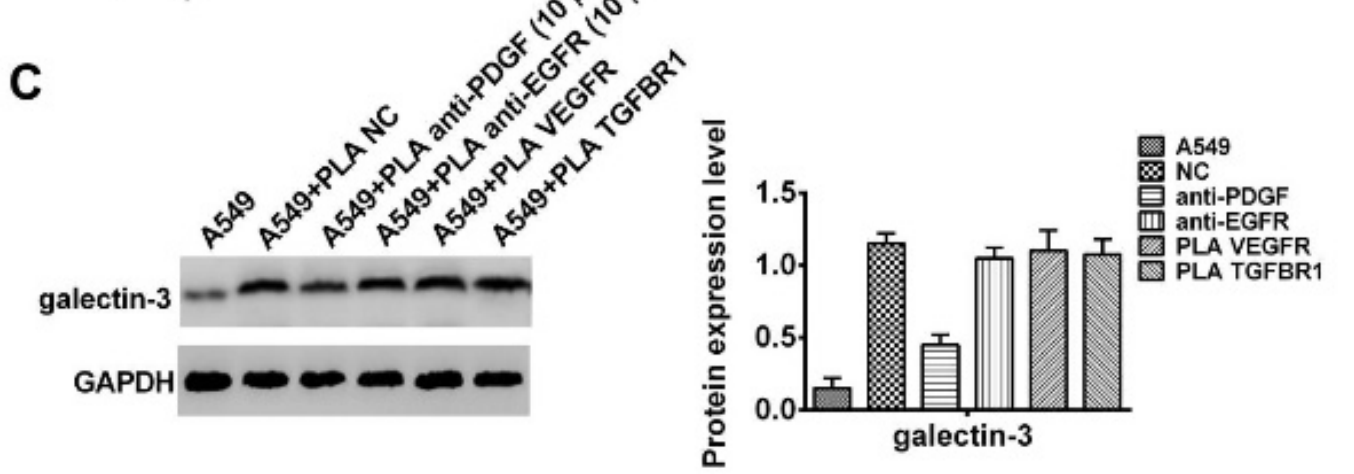

Figure 3: Btk signalling upregulated galectin-3 expression in a positive feedback manner. (A) Co-cultures of platelets and A549 cells were treated with ibrutinib $(3$ and $10 \mu \mathrm{M})$ for $24 \mathrm{~h}$. mRNA levels of galectin-3 were determined with RT-qPCR. (B) Platelets and A549 cells co-cultures were treated with ibrutinib (3 and $10 \mu \mathrm{M})$ for 24 h. Galectin-3 protein levels were assessed using western blotting. (C) Platelets and A549 cells co-cultures were treated with Abs against PDGF $(10 \mu \mathrm{g} / \mathrm{mL})$, EGF $(10 \mu \mathrm{g} / \mathrm{mL})$, VEGF $(10 \mu \mathrm{g} / \mathrm{mL})$, or TGF $\beta 1(10 \mu \mathrm{g} / \mathrm{mL})$ for $48 \mathrm{~h}$. Galectin-3 protein levels were determined using western blotting. The histograms show grayscale value using Glyco Band-Scan software. ${ }^{*} p<0.01$ vs mock control and ${ }^{\# \#} p<0.01$ vs DMSO control. DMSO = dimethyl sulfoxide (control buffer)

binding to platelet collagen receptor GPVI [13]. Based on these results, the hypothesis is that galectin-3 mediated the A549 induced BTK activation in platelets. In the current study, the data indicate that specific inhibition of galectin-3 with siRNA or inhibitor significantly blocked the activation of BTK. However, activated platelets contributed to cancer progression through the release of various factors with pro-tumour activity, such as PDGF during platelet activation [19]. As the mRNA and protein level of galectin-3 can be regulated by various stimuli [20], the involvement of PDGF in the overexpression of galectin-3 in A549 cells was investigated. Importantly, the data demonstrated that Btk signalling upregulated galectin-3 expression in a positive feedback manner in A549 cells.

Ibrutinib was recently reported to regulate the growth of solid tumors via modulation of the immune system [21]. Ibrutinib is very effective at suppressing the growth of pancreatic ductal adenocarcinoma (PDAC) in both transgenic mouse and patient-derived xenograft models of the disease [22]. Moreover, treatment of PDAC mice with ibrutinib enhanced CD8 T-cell frequency and suppressed tumour growth [23]. In the present study, the results showed that ibrutinib inhibited cell viability, migration, and invasion in A549 cells by blocking the crosstalk between A549 cells and platelets.

\section{CONCLUSION}

These findings show that A549 cells induce platelet activation via galectin-3/BTK signalling. Conversely, activated platelets promotes galectin-3 expression via the release of PDGF, and pharmacological BTK treatment with ibrutinib significantly inhibites cell viability, migration, and invasion in A549 cells. These results, therefore, suggest a novel therapeutic strategy for the treatment of lung cells with ibrutinib. 
A
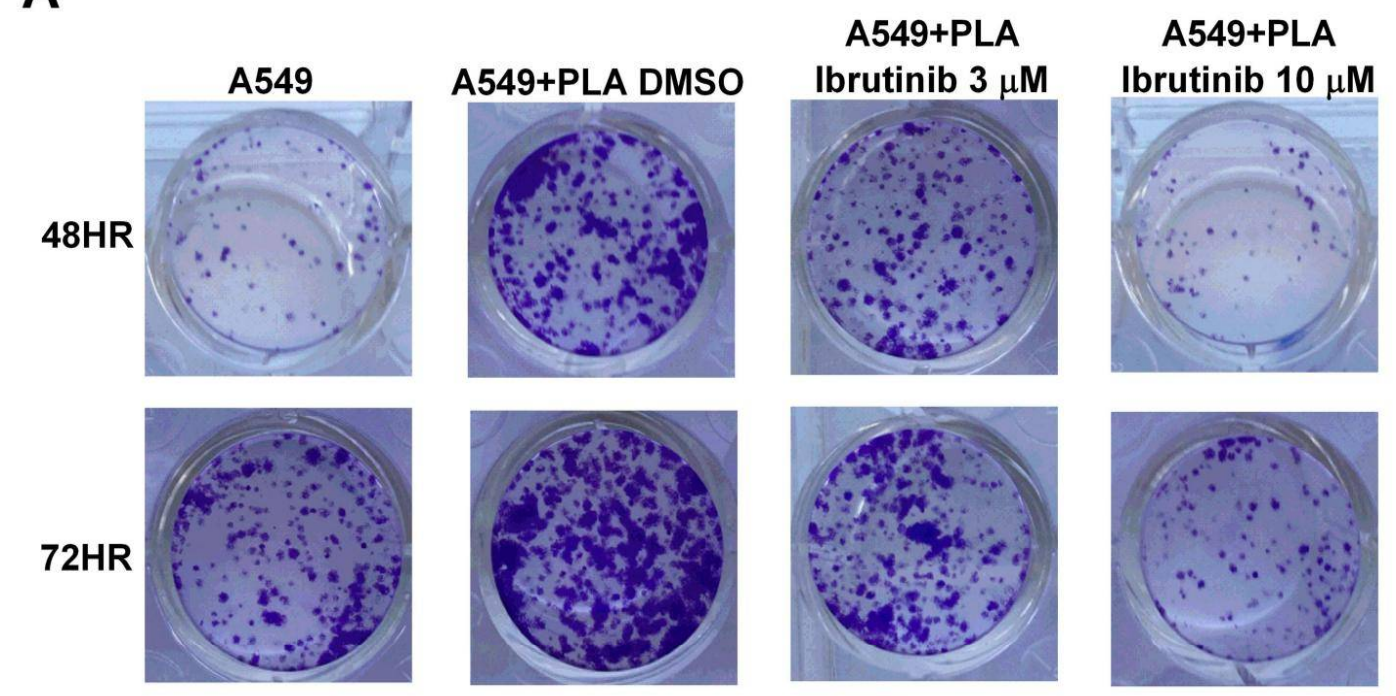

B
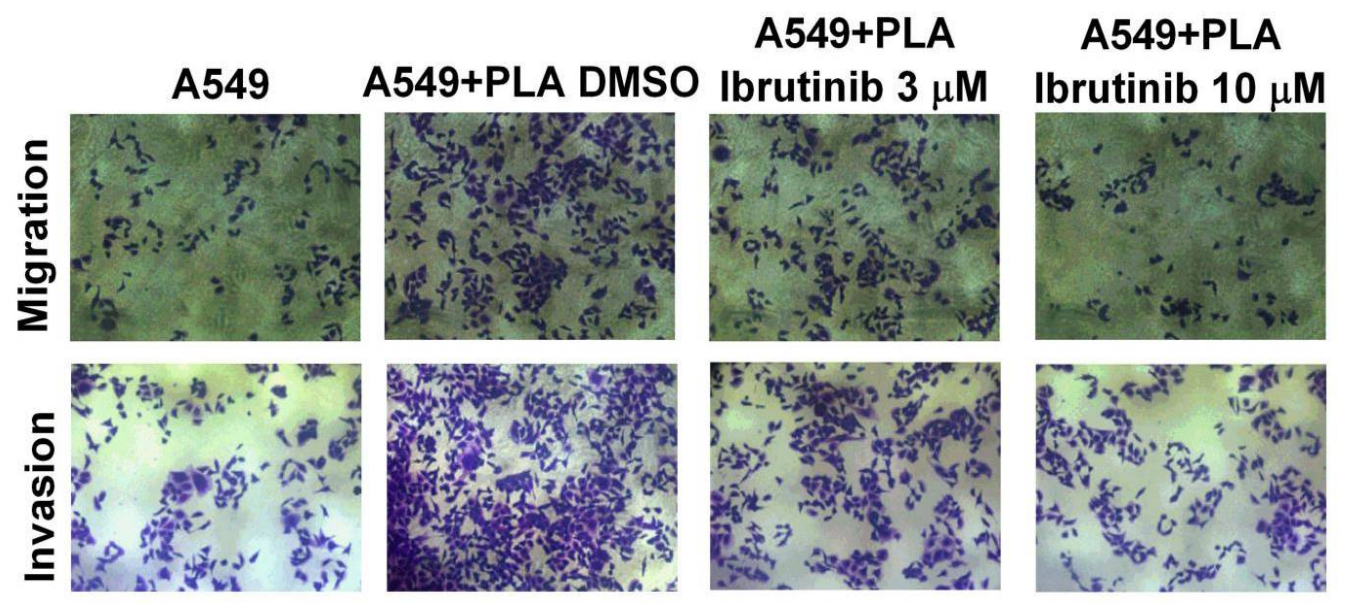

Figure 4: Ibrutinib inhibited co-culture-induced proliferation, invasion and migration capabilities of A549 tumour cells. (A) Colony formation assays were performed in co-cultures of A549 cells and platelets treated with ibrutinib ( 3 and $10 \mu \mathrm{M}$ ) for 10 days. Co-cultures of A549 cells and platelets were treated with ibrutinib ( 3 and $10 \mu \mathrm{M}$ ) for 12 $h$ and cell migration (B) and invasion (C) were analysed using Transwell ${ }^{\Theta}$ assays; $p<0.01$ vs mock control and $\# p<0.01$ vs DMSO control. DMSO = dimethyl sulfoxide (control buffer)

\section{DECLARATIONS}

\section{Conflict of Interest}

No conflict of interest associated with this work.

\section{Contribution of Authors}

We declare that this work was done by the authors named in this article and all liabilities pertaining to claims relating to the content of this article will be borne by the authors. Qi Zhou designed all the experiments and revised the paper. Zhiqiang Fu, Haifeng Wang and Yi Zhou performed the experiments, and Zhiqiang $\mathrm{Fu}$ wrote the paper.

\section{REFERENCES}

1. Jiang $L L$, Sun BR, Zheng C, Yang GL. The antitumour effects of eudesmin on lung cancer by inducing apoptosis via mitochondria-mediated pathway in the tumour cells. Pharm Biol 2017; 55(1): 2259-2263.

2. Wise J. Mobile lung cancer testing in supermarket car parks is to be expanded. BMJ 2017; 359: j5450.

3. Smorenburg SM, Van Noorden CJ. The complex effects of heparins on cancer progression and metastasis in experimental studies. Pharmacol Rev 2001; 53(1): 93105.

4. He $A D$, Wang $S P$, Xie $W$, Song $W$, Miao $S$, Yang RP, Zhu Y, Xiang JZ, Ming ZY. Platelet derived TGF-beta promotes cervical carcinoma cell growth by suppressing KLF6 expression. Oncotarget 2017; 8(50): 8717487181. 
5. Bambace NM, Holmes CE. The platelet contribution to cancer progression. J Thromb Haemost 2011; 9(2): 237249.

6. Alonso-Escolano D, Strongin AY, Chung AW, Deryugina El, Radomski MW. Membrane type-1 matrix metalloproteinase stimulates tumour cell-induced platelet aggregation: role of receptor glycoproteins. $\mathrm{Br} \mathrm{J}$ Pharmacol 2004; 141(2): 241-252.

7. Aw A, Brown JR. Current Status of Bruton's Tyrosine Kinase Inhibitor Development and Use in B-Cell Malignancies. Drugs Aging 2017; 34(7): 509-527.

8. Tran PN, O'Brien S. The safety of Bruton's tyrosine kinase inhibitors for the treatment of chronic lymphocytic leukemia. Expert Opin Drug Saf 2017; 16(9): 10791088.

9. Wong WS, Leong KP. Tyrosine kinase inhibitors: a new approach for asthma. Biochim Biophys Acta 2004; 1697(1-2): 53-69.

10. Molina-Cerrillo J, Alonso-Gordoa T, Gajate P, Grande E. Bruton's tyrosine kinase (BTK) as a promising target in solid tumors. Cancer Treat Rev 2017; 58: 41-50.

11. Stephens $G$, O'Luanaigh $N$, Reilly $D$, Harriott $P$, Walker $B$, Fitzgerald $D$, Moran $N$. A sequence within the cytoplasmic tail of Gpllb independently activates platelet aggregation and thromboxane synthesis. J Biol Chem 1998; 273(32): 20317-20322.

12. Gong L, Cai Y, Zhou X, Yang H. Activated platelets interact with lung cancer cells through $P$-selectin glycoprotein ligand-1. Pathol Oncol Res 2012; 18(4): 989-996.

13. Dovizio M, Maier TJ, Alberti S, Di Francesco L, Marcantoni E, Munch G, John CM, Suess B, Sgambato $A$, Steinhilber $D$, et al. Pharmacological inhibition of platelet-tumor cell cross-talk prevents platelet-induced overexpression of cyclooxygenase-2 in HT29 human colon carcinoma cells. Mol Pharmacol 2013; 84(1): 25 40.
14. Atkinson BT, Ellmeier W, Watson SP. Tec regulates platelet activation by GPVI in the absence of Btk. Blood 2003; 102(10): 3592-3599.

15. Ahmed H, AlSadek DM. Galectin-3 as a Potential Target to Prevent Cancer Metastasis. Clin Med Insights Oncol 2015; 9: 113-121.

16. Kuo HY, Hsu HT, Chen YC, Chang YW, Liu FT, Wu CW. Galectin-3 modulates the EGFR signalling-mediated regulation of Sox2 expression via c-Myc in lung cancer. Glycobiology 2016; 26(2): 155-165.

17. O'Driscoll L, Linehan R, Liang $Y H$, Joyce $H$, Oglesby I, Clynes M. Galectin-3 expression alters adhesion, motility and invasion in a lung cell line (DLKP), in vitro. Anticancer Res 2002; 22(6A): 3117-3125.

18. Seguin L, Camargo MF, Wettersten HI, Kato S, Desgrosellier JS, von Schalscha T, Elliott KC, Cosset E, Lesperance J, Weis SM, et al. Galectin-3, a Druggable Vulnerability for KRAS-Addicted Cancers. Cancer Discov 2017.

19. Heldin CH, Lennartsson J, Westermark B. Involvement of platelet-derived growth factor ligands and receptors in tumorigenesis. J Intern Med 2017.

20. Wang L, Guo XL. Molecular regulation of galectin-3 expression and therapeutic implication in cancer progression. Biomed Pharmacother 2016; 78: 165-171.

21. Weber ANR, Bittner Z, Liu X, Dang TM, Radsak MP, Brunner C. Bruton's Tyrosine Kinase: An Emerging Key Player in Innate Immunity. Front Immunol 2017; 8: 1454.

22. Masso-Valles $D$, Jauset $T$, Serrano $E$, Sodir NM, Pedersen K, Affara NI, Whitfield JR, Beaulieu ME, Evan Gl, Elias L, et al. Ibrutinib exerts potent antifibrotic and antitumor activities in mouse models of pancreatic adenocarcinoma. Cancer Res 2015; 75(8): 1675-1681.

23. Gunderson AJ, Kaneda MM, Tsujikawa $T$, Nguyen AV, Affara NI, Ruffell B, Gorjestani S, Liudahl SM, Truitt M, Olson $P$, et al. Bruton Tyrosine Kinase-Dependent Immune Cell Cross-talk Drives Pancreas Cancer. Cancer Discov 2016; 6(3): 270-285. 